\title{
The Effect of Annealing Temperature On The Structural and Optical Properties of Si/SiO2 Composites Synthesized By Thermal Oxidation of Silicon Wafers
}

Kamal Kayed ( $\nabla$ khmk2000@gmail.com )

Damascus University https://orcid.org/0000-0001-9842-9080

Dalal Baba Kurd

Damascus University

\section{Research Article}

Keywords: Silicon Oxide, Thin Film, Annealing, Plasmons, plasma edge

Posted Date: March 1st, 2021

DOI: https://doi.org/10.21203/rs.3.rs-246154/v1

License: (a) This work is licensed under a Creative Commons Attribution 4.0 International License. Read Full License

Version of Record: A version of this preprint was published at Silicon on August 6th, 2021. See the published version at https://doi.org/10.1007/s12633-021-01307-w. 


\section{Abstract}

In this article, silicon wafers were thermal treated in air at temperatures from 800 to $1200{ }^{\circ} \mathrm{C}$. The annealed samples were investigated using X-ray diffraction, FTIR and optical reflection spectroscopy. Unique result obtained includes that, that Kubelk-Munk curves could be utilized to estimate the ratio of oxidized silicon atoms. In addition, we found that these curves could provide information on the degree to which the nanoparticle formation affects both the reflection spectra and the energy gap of the $\mathrm{Si} / \mathrm{SiO}_{2}$ composites. On the other hand, it has been found that, the intensity of the silicon peak in XRD spectra is proportional to the relative absorption coefficient of amorphous silicon oxide.

\section{Introduction}

The oxidation of silicon surfaces shows promising properties that have made them the focus of many research groups [1-23], which have sought to employ various silicon oxidation techniques in the fabrication of semiconductor devices. These oxidized layers can be used as a key ingredient in creating many electronic devices such as, passivated contacts in silicon solar cells [1, 2], multi-junction quantum well solar cells $[7,8]$, and barrier layer in silicon-based single and passivation of the amorphous/crystalline Si (a-Si:H/c-Si) heterojunction [4-6], etc.

Thermal oxidation of silicon wafers occurs according to two different mechanisms. At high oxygen gas pressures and low temperature $\mathrm{SiO}_{2}$ layer growth takes place (passive oxidation) according to the reaction $\mathrm{Si}+\mathrm{O}_{2} \rightarrow \mathrm{SiO}_{2}$ [24]. This oxidation method is suitable for industrial applications, although there is no theoretical model that explains how the oxidation process occurs according to this method in the case of ultrathin films [25]. In the case of low oxygen gas pressures and high temperature, SiO is desorbed in an etching process (active oxidation) according to the reaction $2 \mathrm{Si}+\mathrm{O}_{2} \rightarrow 2 \mathrm{SiO}$. In this case, the silicon surface remains free of oxide [24] with the possibility of formation of volatile SiO because of high temperature $\mathrm{SiO}_{2} / \mathrm{Si}$ decomposition via the apparent reaction $\mathrm{Si}+\mathrm{SiO}_{2} \rightarrow 2 \mathrm{SiO}$ when the oxygen pressure is low. In the other hand, the reoxidation reaction is also possible [24]. Silicon oxide decomposition can be used to help obtain a clean silicon surface [26], but at the same time, the electrical properties of silicon can be damaged because of this process. In fact, passive oxidation (formation of $\mathrm{SiO}_{2}$ ), active oxidation (formation of $\mathrm{SiO}$ (gas)) and $\mathrm{SiO}_{2}$ decomposition are considered separately, with the exception of the transition regime and the first monolayer stage of passive oxidation where these reactions are competitive. The transport of the silicon monoxide $(\mathrm{SiO})$ into gas phase has been noticed only during active oxidation and oxide decomposition processes in vacuum [24]. The processes of decomposition and transition to the gas phase are important factors in determining the growth mechanism of silicon oxide layers

In silicon oxide layers, silicon nanostructures may be present in the silicon oxide matrix. The, nucleation of Si nanoparticles is induced by a high temperature during the oxidation process. Depending on the deposition conditions and on the temperature and duration of the annealing processes, it is possible to obtain crystalline or amorphous aggregates Si-nc with different sizes and distributions embedded into a 
SiO $x$ matrix [27]. The presence of such nanoformations in the structure of silicon oxide greatly influences its overall electrical and optical properties.

In this work, we present the results of investigating the structural and optical properties of $\mathrm{Si} / \mathrm{SiO}_{2}$ composites synthesized by thermal oxidation of silicon wafers, where we highlight the important effect of the effect of thermally induced structural changes on the main features of the Kubelk-Munk curves.

\section{Experimental}

\subsection{Sample preparation}

Thoroughly cleaned Pure n-type Si(111) wafers (99.99\%) were thermal treated in air at temperatures from 800 to $1200{ }^{\circ} \mathrm{C}$ using an oven in order to oxidize the silicon atoms. Table 1 contains the thermal treatment conditions for each sample.

Table 2: The thermal treatment conditions for each sample.

\begin{tabular}{|lll|}
\hline Sample code & $\begin{array}{l}\text { Temperature } \\
(\boldsymbol{\bullet})\end{array}$ & Thermal processing time (hr) \\
\hline A & - & - \\
\hline B & 800 & 4 \\
\hline C & 900 & 4 \\
\hline D & 1000 & 4 \\
\hline E & 1100 & 4 \\
\hline F & 1200 & 4 \\
\hline
\end{tabular}

\subsection{Sample characterization}

The chemical composition of the samples was examined by using a FTIR spectrophotometer (JASCO4200 ) in the range $400-1300 \mathrm{~cm}^{-1}$, with resolutions of $4 \mathrm{~cm}^{-1}$. The crystallite structure of the films was measured by $\mathrm{X}$-ray diffraction (XRD) using Philips Analytical X-Ray diffractometer employing a $\mathrm{Cu} \mathrm{Ka}_{1}(\lambda$ $=1.54060 \AA$ ) source. The optical reflection spectra were recorded with a UV-Vis spectrophotometer (Cary $5000)$.

\section{Results And Discussion}

X-ray diffraction measurements were carried out on all prepared samples. The spectra did not show any characteristic Bragg peaks for silicon oxide, indicating the amorphous structure of this oxide. Fig. 1 
contains a sample of the XRD spectra that we obtained, which is related to the sample annealed at $1200^{\circ}$ C (sample F). In all measured XRD spectra, the sharp peak is related to Si (111) (CSM card no. 65-1060).

Fig. 2 shows the infrared vibrations observed in the FTIR spectra of the annealed samples. The broad and intense band at $997-1142 \mathrm{~cm}^{-1}$ and the peak at $640 \mathrm{~cm}^{-1}$ are attributed to the Si-O-Si stretching vibrations [28]. The peak observed at $813 \mathrm{~cm}^{-1}$ is assigned to Si-O-Si bending vibrations [28, 29]. The absorption peak at $461 \mathrm{~cm}^{-1}$ is due to Si-O-Si rocking vibrations [28]. The weak band located at $419 \mathrm{~cm}^{-1}$ and the peak at $619 \mathrm{~cm}^{-1}$ could be originated from Si-O pounds [28]. The shoulder at $1190 \mathrm{~cm}^{-1}$ appears due to a splitting of longitudinal optical and transverse optical stretching motions [30].

We notice that, for all peaks, the intensity increases with increasing oxidation temperature, indicating that the oxidation rate increases with increasing temperature.

Fig. 3 shows the reflectance spectra of the prepared samples

We notice that, the spectra are overlapping and the effect of annealing on the reflectivity is not carried out in a specific direction and that for most wavelengths the value of the reflectivity does not exceed the reflectivity in the case of the non-annealed sample. On the other hand, despite the tendency of reflectivity to decrease with increasing wavelength, the decrease associated with the appearance of two peaks in the range $\lambda<400 \mathrm{~nm}$ in all spectra and these peaks are a result of the interaction of light with silicon nanoparticles plasmons. The appearance of two plasma edges in each spectrum is due to the nanoparticles having two different sizes [31, 32]. In addition to the mentioned plasma absorption edges, we observe three additional edges in the range $\lambda>400 \mathrm{~nm}$ in the spectra $D$ (at $600 \mathrm{~nm}$ ), $E($ at $405 \mathrm{~nm}$ ) and $\mathrm{F}($ at $516 \mathrm{~nm}$ ). We believe that these edges are a consequence of defects in the silicon oxide structure caused by the phenomena of splitting of longitudinal optical and transverse optical stretching motions of the bonds $\mathrm{Si}-\mathrm{O}-\mathrm{Si}$, which was observed during the analysis of the FIR spectra (Fig 2).

It is known that, samples with plasma edges with short wavelengths have high concentrations of charge carriers [31, 32]. By applying this rule to Fig. 4 that illustrates the position of each plasma edge as a function of annealing temperature, we conclude that plasma edge 1 in all spectra represents the case of Si nanoparticles with high charge carrier concentration.

Because the prepared films were opaque, we calculated the optical energy band gap from the reflectance spectra using Kubelk-Munk method [33, 34]. Fig. 5 shows the method of calculating the energy band for each sample. In this figure, $F(R)$ is a function of the reflectivity $R$ at the wavelength $\lambda$. This function represents the absorption coefficient and given by the formula [33, 34]:

$$
\mathrm{F}(\mathrm{R})=\ln \left(\frac{\left(R_{\max }-R_{\min }\right)}{\left(R-R_{\min }\right)}\right)
$$


The optical energy band gap (Eg) was calculated by assuming direct transitions between the valence band and the conduction band.

We observe that there are multiple absorption edges in each spectrum (more than one energy band gap). The non-annealed sample (sample A) spectrum contains three absorption edges, one of them belonging to the silicon and the others belonging to the nanoparticles. These edges appear in the rest of the samples, despite the occurrence of oxidation processes. The absorption edge of silicon oxide appears in all spectra of the annealed samples except for the curve of sample B. However, an absorption peak of silicon oxide can be observed in sample B curve in Fig. 6, which shows the absorption coefficient as a function of the wavelength for each sample. This result indicates that the oxide molecules in sample B do not form a continuous coherent structure. On the other hand, the appearance of the silicon absorption edge in all spectra in Figs. 5 and 6 can be explained by the lack of a complete oxidation of the sample surface during the thermal treatment.

The presence of the absorption edge of both silicon and silicon oxide helps to detect the degree of oxidation by comparing the values of the absorption coefficients at wavelength maxima both silicon and silicon oxide. Since the oxide layer does not have the same thickness in every sample, it is necessary to adopt the relative absorption coefficient, which equals the ratio between the absorption coefficient of the silicon oxide and the absorption coefficient of the silicon $\left(a_{\text {oxide }}=F(R)_{S i} / F(R)_{\text {oxide. }}\right.$. Fig. 7 represents the relative absorption coefficient as a function of the annealing temperature.

In this figure, the oxidation rate appears to increase with increasing annealing temperature within the region $800-1000^{\circ} \mathrm{C}$. The annealing at $1100^{\circ} \mathrm{C}$ causes a sharp decrease in the $\mathrm{a}_{\text {oxide }}$ parameter value. Conversely, the annealing at $1200^{\circ} \mathrm{C}$ leads to an increase in this parameter value. The reason for the decrease in both the absorption coefficient and the relative absorption coefficient of silicon oxide in the case of sample $E$ is the presence of the edge that resulting from the defects in the silicon oxide structure (Fig 3) near the edge of the silicon oxide (Fig 6).

We mentioned that the silicon oxide formed due to oxidation processes is not amorphous; although it can be guessed that the oxide layer formed on the surface of the silicon wafer affects some of the characteristics of the silicon peak that appear in the XRD spectra. Fig. 8 illustrates the XRD silicon (111) peak as a function of the coefficient $a_{\text {oxide. }}$

We notice that, with the exception of sample A that has low oxygen content, the intensity of the silicon peak increases linearly with increasing the relative absorption coefficient. This result is important because it attributes the decrease in the intensity of the silicon peak in the XRD spectra to an increase in the surface oxidation rate.

Fig. 9 shows the optical band gap of silicon oxide as a function of annealing temperature. We notice that the band gap increases with increasing annealing temperature in the range $800-1000{ }^{\circ} \mathrm{C}$. Once moving 
to the region of samples with a stressed silicon oxide structure $\left(1100-1200^{\circ} \mathrm{C}\right)$, the band gap begins to decrease with the increase in the annealing temperature.

Fig. 10 shows the optical band gap of silicon as a function of annealing temperature. We notice that the band gap of silicon also increases with increasing annealing temperature in the range $800-1100{ }^{\circ} \mathrm{C}$. We also notice that, increasing the annealing temperature to $1200^{\circ} \mathrm{C}$ decreases the energy gap value.

It is important to assess the effect of the formation of nanoparticles on the optical properties of the prepared samples. For this purpose, we defined the relative absorption coefficients of the nanoparticles observed in the Figs 5 and 6 , in a manner similar to the definition of the relative absorption coefficient of silicon oxide. Fig. 11 illustrates the relative absorption coefficients of the nanoparticles as a function of the annealing temperature.

We notice that, the effect of the formation of nanoparticles on the absorption coefficient is evident in the case of the sample $C$ and to a lesser extent in the case of the sample $E$.

\section{Conclusion}

In this work, pure n-type Silicon (111) wafers were thermal treated at different annealing temperatures. Annealing processes were performed in the air using an oven. The effect of temperature on XRD and reflectance spectra of the prepared films was studied. The results obtained included the following:

- The edges observed in the reflection spectra are attributed to both the silicon nanoparticles plasmons and the phenomena of splitting of longitudinal optical and transverse optical stretching motions of the bonds $\mathrm{Si}-\mathrm{O}-\mathrm{Si}$.

- There are multiple absorption edges in each Kubelk-Munk curve (more than one energy band gap). These edges are located in the absorption domains of silicon, amorphous silicon oxide and silicon nanoparticles (two edges).

- The annealing at $1000^{\bullet} \mathrm{C}$ for four hours provides almost complete oxidation.

- The presence of the absorption edge of both silicon and silicon oxide helps to detect the degree of oxidation by comparing the values of the absorption coefficients at wavelength maxima both silicon and silicon oxide.

- The intensity of the silicon peak increases linearly with increasing the relative absorption coefficient.

- The effect of the formation of nanoparticles on the absorption coefficient is evident in the case of the sample $\mathrm{C}$ and to a lesser extent in the case of the sample $\mathrm{E}$.

\section{Declarations}

\section{Acknowledgments}


The authors would like to thank the University of Damascus and the Higher Institute for Applied Sciences and Technology for providing the facility to carry out this research.

\section{References}

1. F. Feldmann, M. Bivour, C. Reichel, H. Steinkemper, M. Hermle, S.W. Glunz, Tunnel oxide passivated contacts as an alternative to partial rear contacts, Sol. Energy Mater. Sol. Cells, 131 (2014) 46-50.

2. A. Moldovan, F. Feldmann, M. Zimmer, J. Rentsch, J. Benick, M. Hermle, Tunnel oxide passivated carrier-selective contacts based on ultra-thin SiO2 layers, Solar Energy Materials and Solar Cells, 142 (2015) 123-127.

3. M.A. Green, R.B. Godfrey, MIS solar cell - General theory and new experimental results for silicon, Applied Physics Letters, 29 (1976) 610-612.

4. J.Y. Bian, L.P. Zhang, W.W. Guo, D.L. Wang, F.Y. Meng, Z.X. Liu, Improved passivation effect at the amorphous/crystalline silicon interface due to ultrathin SiOx layers pre-formed in chemical solutions, Applied Physics Express, 7 (2014) 065504.

5. J.P. Seif, A. Descoeudres, M. Filipiè, F. Smole, M. Topiè, Z. Charles Holman, S. De Wolf, C. Ballif, Amorphous silicon oxide window layers for high-efficiency silicon heterojunction solar cells, Journal Of Applied Physics, 115 (2014) 024502.

6. K. Ohdaira, T. Oikawa, K. Higashimine, H. Matsumura, Suppression of the epitaxial growth of Si films in Si heterojunction solar cells by the formation of ultra-thin oxide layers, Current Applied Physics, 16 (2016) 1026-1029.

7. R. Rölver, B. Berghoff, D. Bätzner, B. Spangenberg, H. Kurz, M. Schmidt, B. Stegemann, Si/SiO2 multiple quantum wells for all silicon tandem cells: Conductivity and photocurrent measurements, Thin Solid Films, 516 (2008) 6763-6766.

8. B. Stegemann, A. Schoepke, M. Schmidt, Structure and photoelectrical properties of SiO2/Si/SiO2 single quantum wells prepared under ultrahigh vacuum conditions, Journal of Non-Crystalline Solids, 354 (2008) 2100.

9. S.W. Glunz, F. Feldmann, A. Richter, M. Bivour, C. Reichel, H. Steinkemper, J. Benick, M. Hermle, The Irresistible Charm of a Simple Current Flow Pattern - 25\% with a Solar Cell Featuring a Full-Area Back Contact, in: 31st European Photovoltaic Solar Energy Conference, 2015, pp. 259 - 263.

10. F.J. Grunthaner, P.J. Grunthaner, Chemical and electronic structure of the SiO2/Si interface, Materials Science Reports, 1 (1986) 65.

11. F.J. Himpsel, F.R. McFeely, A. Taleb-lbrahimi, J.A. Yarmoff, G. Hollinger, Microscopic structure of the SiO2/Si interface, Phys. Rev. B, 38 (1988) 6084-6096.

12. K. Hirose, H. Nohira, K. Azuma, T. Hattori, Photoelectron spectroscopy studies of SiO2/Si interfaces, Progr. Surf. Sci., 82 (2007) 3.

13. M.T. Sieger, D.A. Luh, T. Miller, T.C. Chiang, Photoemission Extended Fine Structure Study of the SiO_\{2\}/Si(111) Interface, Physical Review Letters, 77 (1996) 2758. 
14. D.A. Luh, T. Miller, T.C. Chiang, Statistical Cross-Linking at the Si(111)/SiO_\{2\} Interface, Physical Review Letters, 79 (1997) 3014.

15. K.L. Brower, Kinetics of $\mathrm{H} 2$ passivation of $\mathrm{Pb}$ centers at the (111) Si-SiO2 interface, Physical Review B, 38 (1988) 9657-9666.

16. H. Flietner, Spectrum and Nature of Defects at Interfaces of Semiconductors with Predominant Homopolar Bonding, Surface Science, 200 (1988) 463-471.

17. B.E. Deal, A.S. Grove, General Relationship for the Thermal Oxidation of Silicon, J. Appl. Phys., 36 (1965) 3770.

18. T. Hattori, Chemical Structures of the SiO2Si Interface, Critical Reviews in Solid State and Materials Sciences, 20 (1995) 339-382.

19. O. Buiu, G. Kennedy, M. Gartner, S. Taylor, Structural analysis of silicon dioxide and silicon oxynitride films produced using an oxygen plasma., IEEE Transactions on Plasma Science, 26 (1998) 17001712.

20. D.W. Hess, Plasma-assisted oxidation, anodization, and nitridation of silicon, IBM Journal of Research and Development, 43 (1999) 127-145.

21. S.K. Sharma, B.C. Chakravarty, S.N. Singh, B.K. Das, Oxidation of silicon in RF induced oxygen plasma, Journal of Materials Science Letters, 9 (1990) 982-984.

22. M.A. Szymanski, A.M. Stoneham, A. Shluger, The different roles of charged and neutral atomic and molecular oxidising species in silicon oxidation from ab initio calculations, Solid- State Electr., 45 (2001) 1233.

23. H. Angermann, Conditioning of Si-interfaces by wet-chemical oxidation: Electronic interface properties study by surface photovoltage measurements, Applied Surface Science, 312 (2014) 3-16.

24. D. Starodub, E. P. Gusev, E. Garfunkel, T. Gustafsson, Silicon oxide decomposition and desorption during the thermal oxidation of silicon, Surface Review and Letters, 6 (1999) 45-52.

25. Fundamental Aspects of Ultrathin Dielectrics on Si-Based Devices, eds. E. Garfunkel, E. Gusev and A. Vul' (Kluwer, Dordrecht/Boston/London, 1998).

26. A. Ishizaka and Y. Shiraki, J. Electrochem. Soc. 133 (1986) 666.

27. N. Daldosso, G. Das, S. Larcheri, G. Mariotto, G. Dalba, L. Pavesi, A. Irrera, F. Priolo, F. Iacona, F. Rocca, Silicon nanocrystal formation in annealed silicon-rich silicon oxide films prepared by plasma enhanced chemical vapor deposition, JOURNAL OF APPLIED PHYSICS 101 (2007) 113510.

28. F. Chau, N. Hong, C. Yan, Synthesis and characterization of silicon oxide nanoparticles using an atmospheric DC plasma torch, Advanced Powder Technology 2 (2018) 220-229.

29. K. Kayed, B. Chiyah, The Structural and Optical Properties of Silver Oxide Thin Films Synthesized by Thermal Evaporation of Silver with Subsequent Annealing, Aerosol Science and Engineering 4(2020) 271-276.

30. P.Lange, W.Windbracke, Characterization of thermal and deposited thin oxide layers by longitudinal optical-transverse optical excitation in fourier transform IR transmission measurements, Thin Solid 
Films 174 (1989) 159-164.

31. K. Kayed, L. Alberni,The Effect of Annealing Temperature on the Plasma Edge in Reflectance Spectra of $\mathrm{Al} / \mathrm{Al}_{2} \mathrm{O}_{3}$ Composites Synthesized by Thermal Oxidation of Aluminum Thin Films, Plasmonics 15(2020) 1959-1966.

32. K. Kayed, The Optical Properties of Individual Silver Nanoparticles in $\mathrm{Ag} / \mathrm{Ag}_{2} \mathrm{O}$ Composites Synthesized by Oxygen Plasma Treatment of Silver Thin Films, Plasmonics 15(2020) 1439-1449.

33. Kubelka P, Munk F (1931) Ein beitrag zur optik der farbanstriche. Z Tech Phys 12:593-601.

34. Kubelka P (1948) New contributions to the optics of intensely lightscattering materials. Part I. J Opt Soc Am 38:448-457.

\section{Figures}

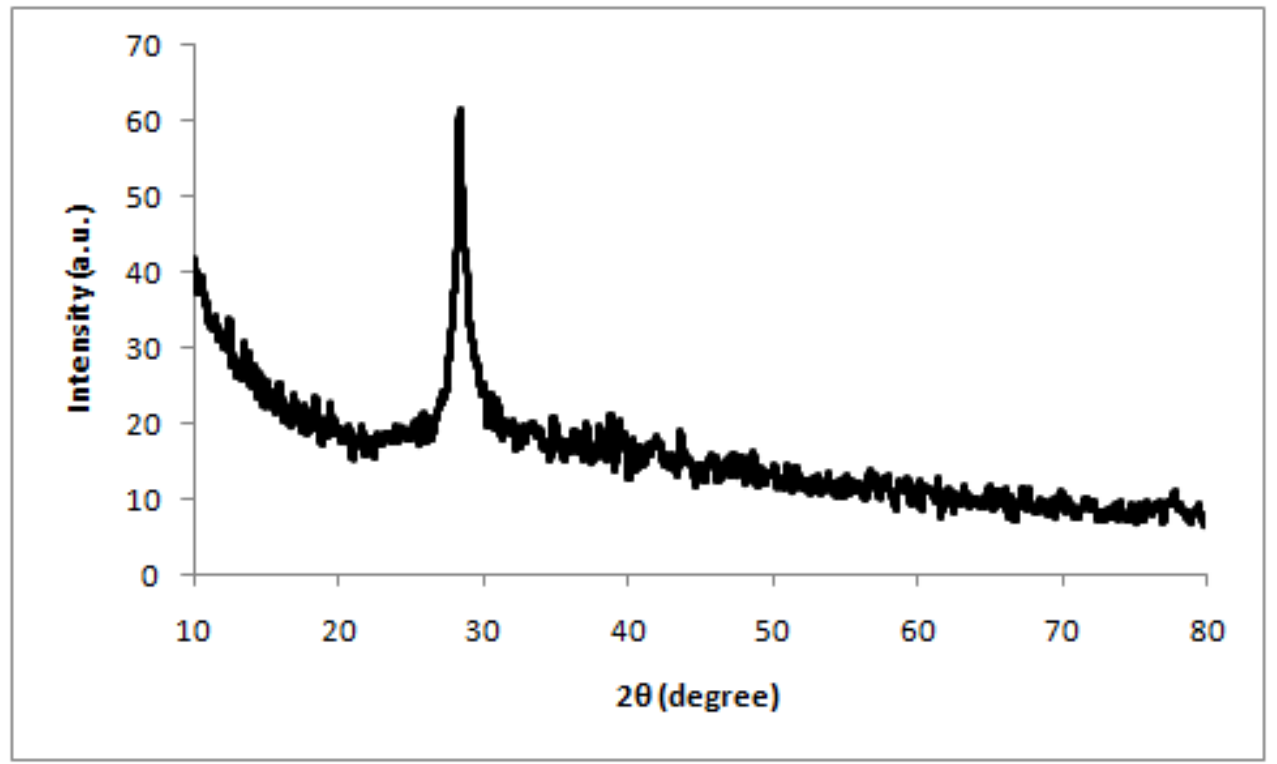

\section{Figure 1}

The XRD spectra of the sample F. 


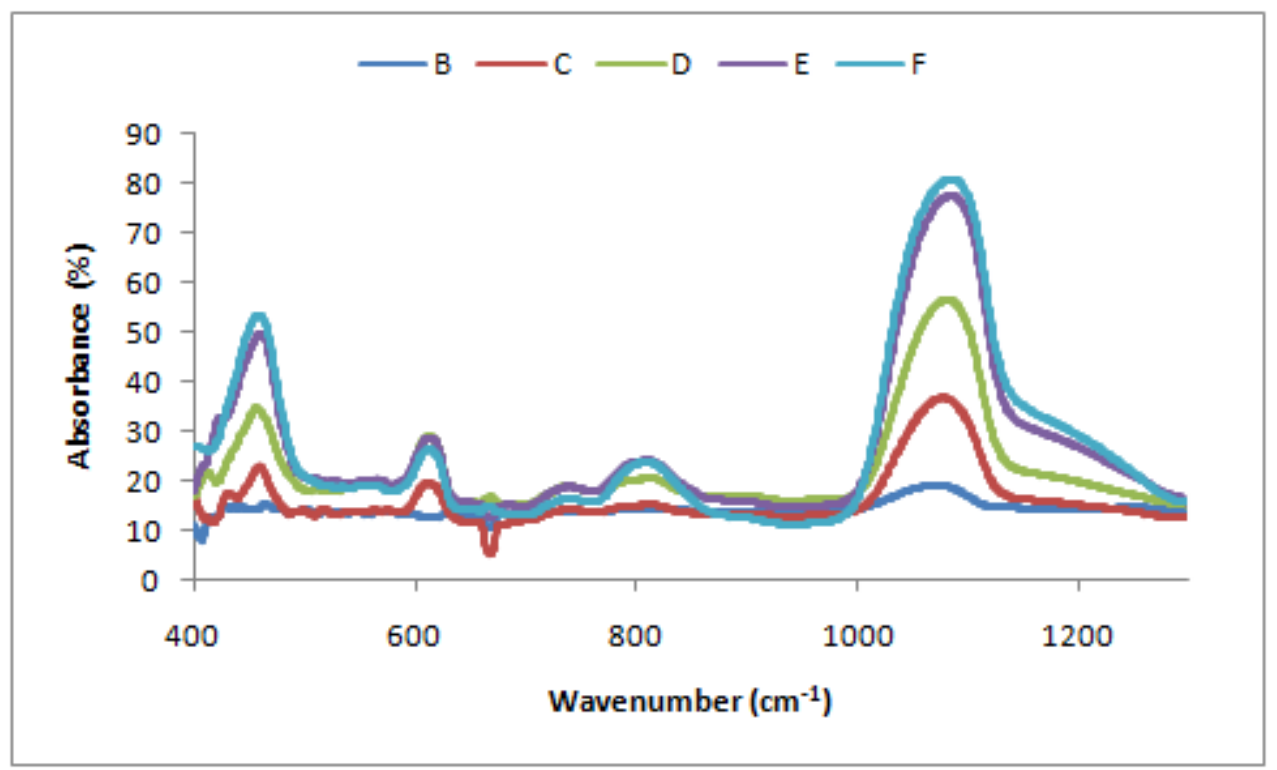

Figure 2

Infrared absorption spectra as a function of annealing temperature for the thermal treated samples. 


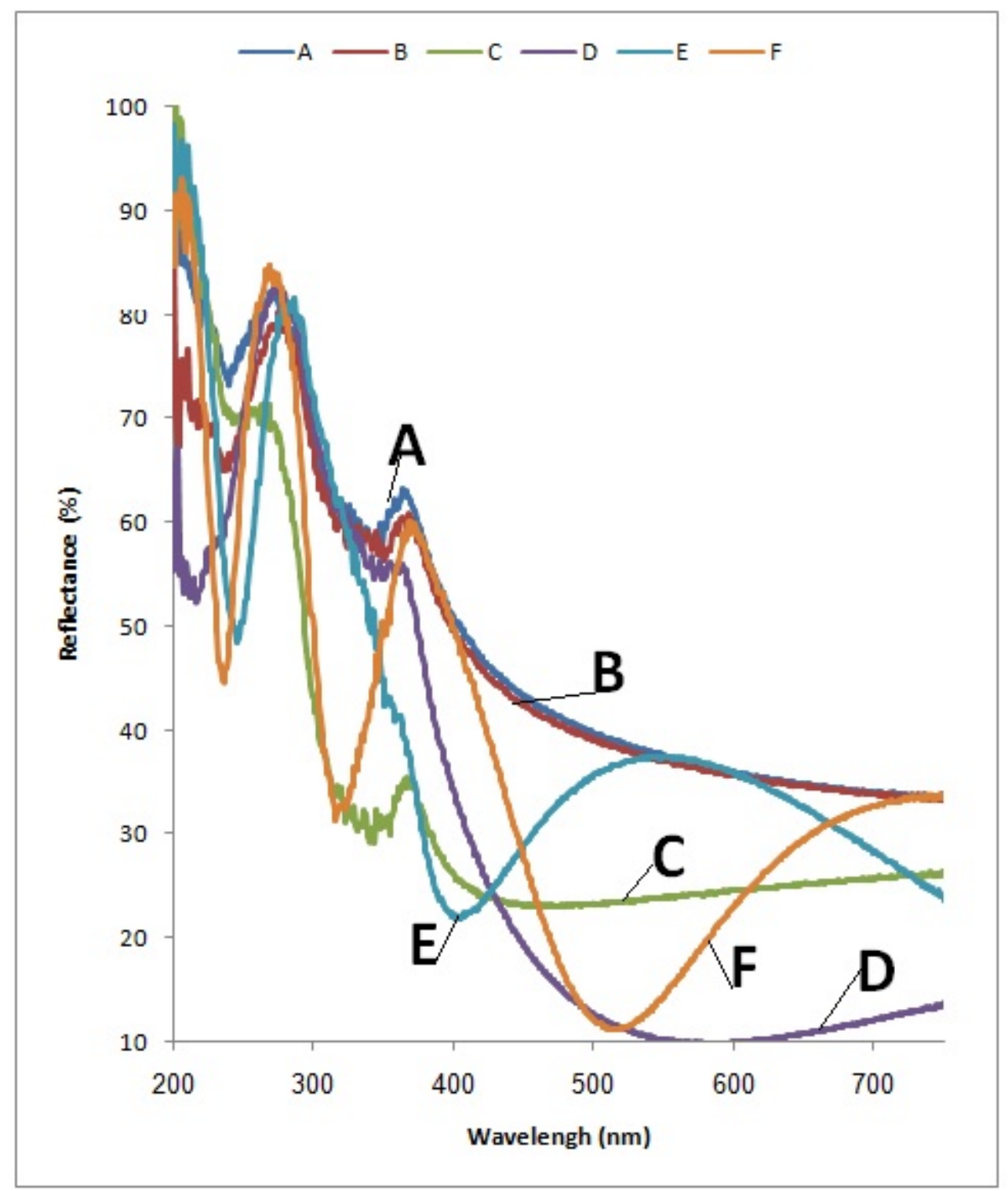

Figure 3

The reflectance spectra of the prepared samples. 


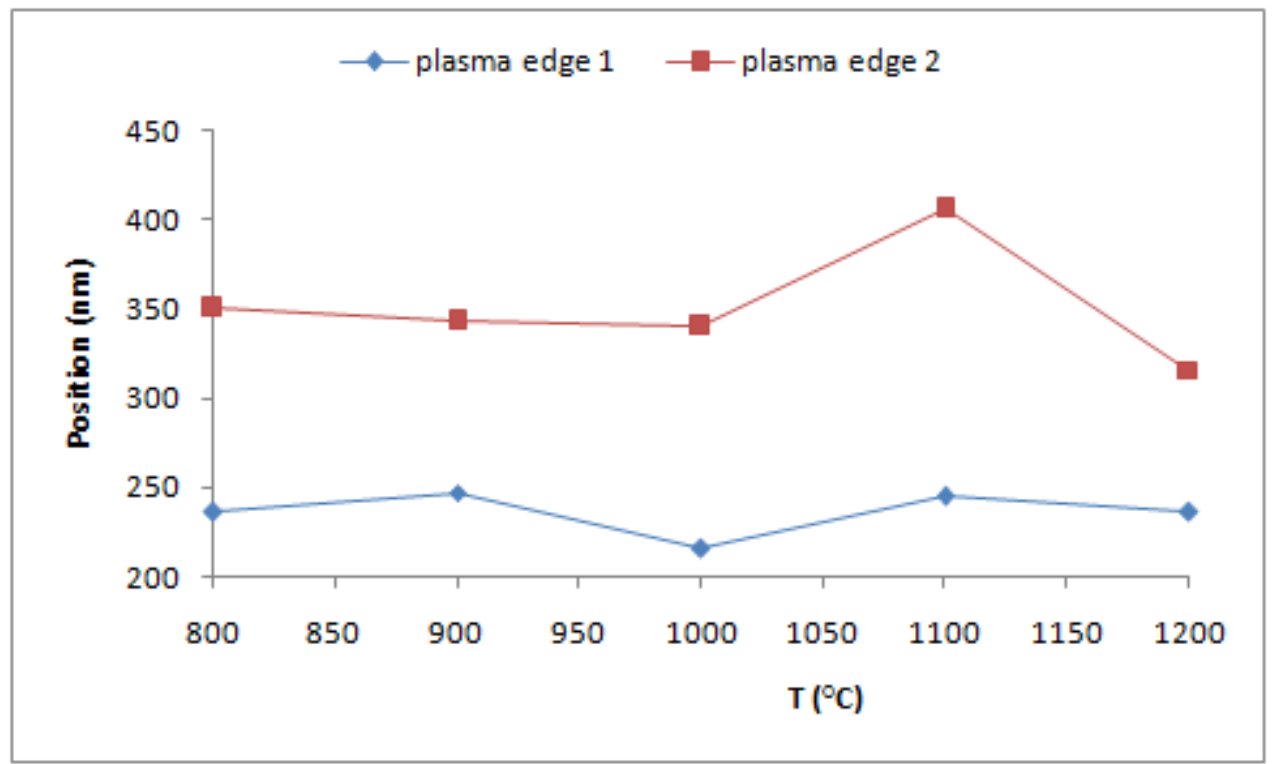

Figure 4

Plasma edge position as a function of annealing temperature.
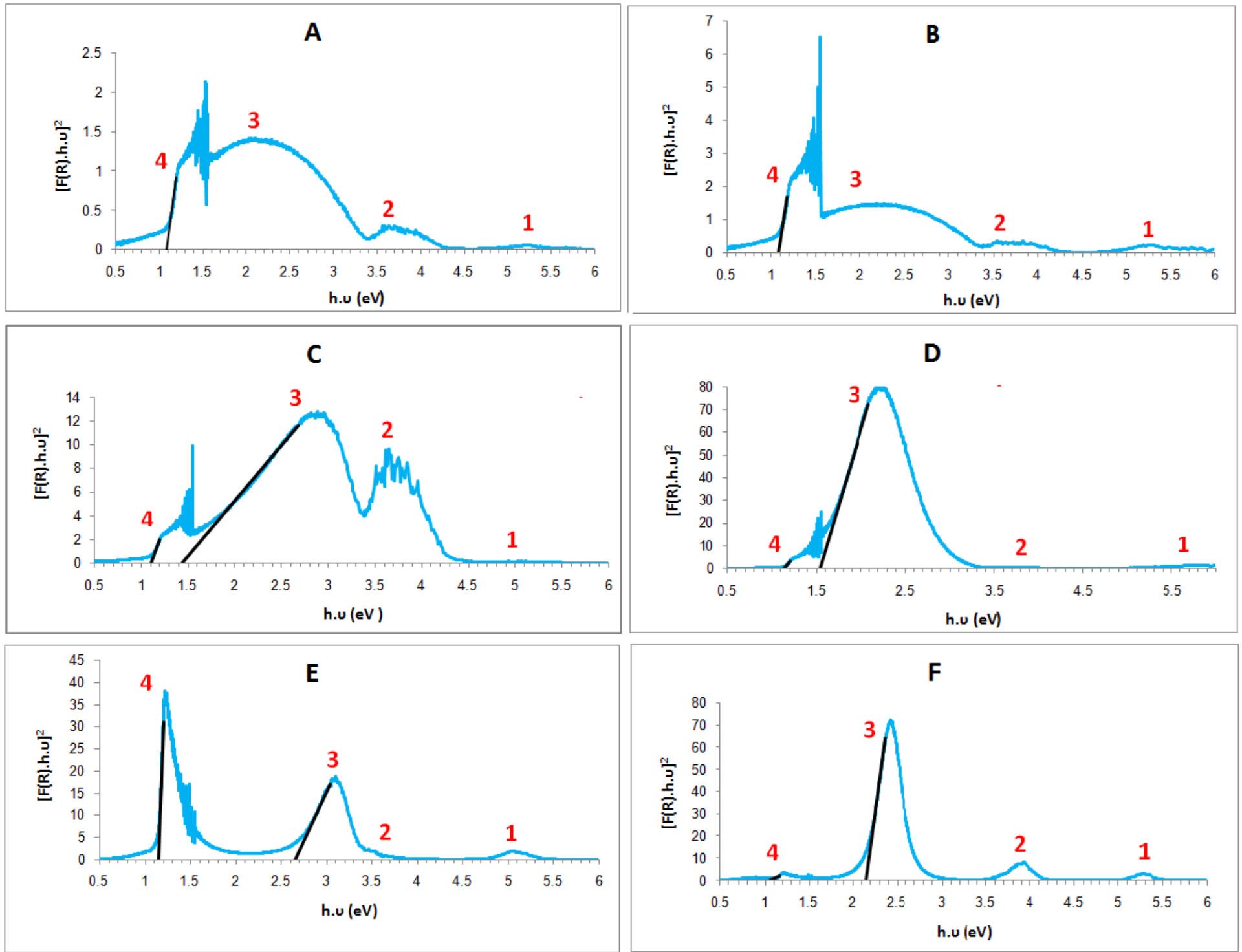
Figure 5

Variation of $(F(R) . h \rrbracket) 2$ against $h \rrbracket$ for each sample (1: NPs1; 2: NPs2; 3: SiOx; 4: Si).
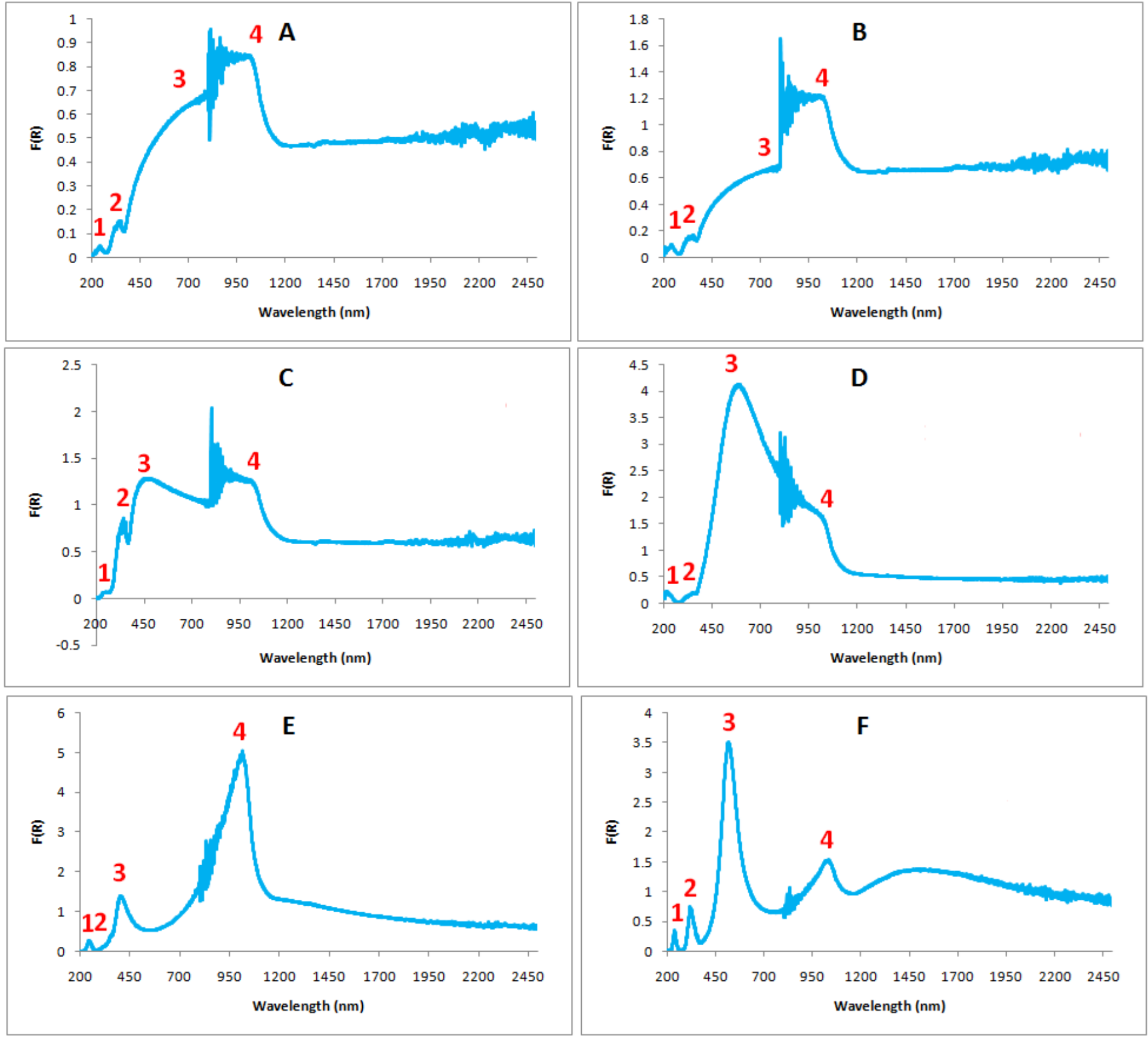

\section{Figure 6}

The absorption coefficient $(F(R))$ as function of wavelength for each sample (1: NPs1; 2: NPs2; 3: SiOx; 4: $\mathrm{Si})$. 


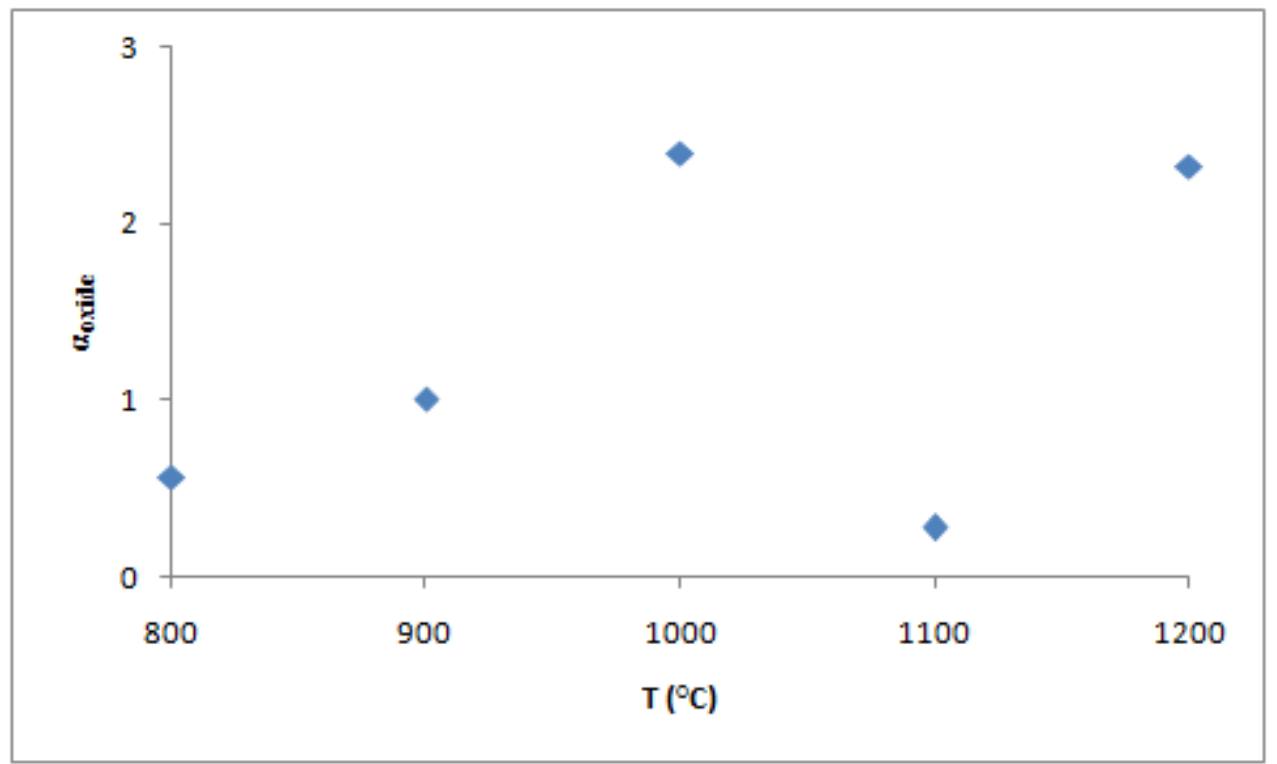

Figure 7

The coefficient aoxide as function of annealing temperature.

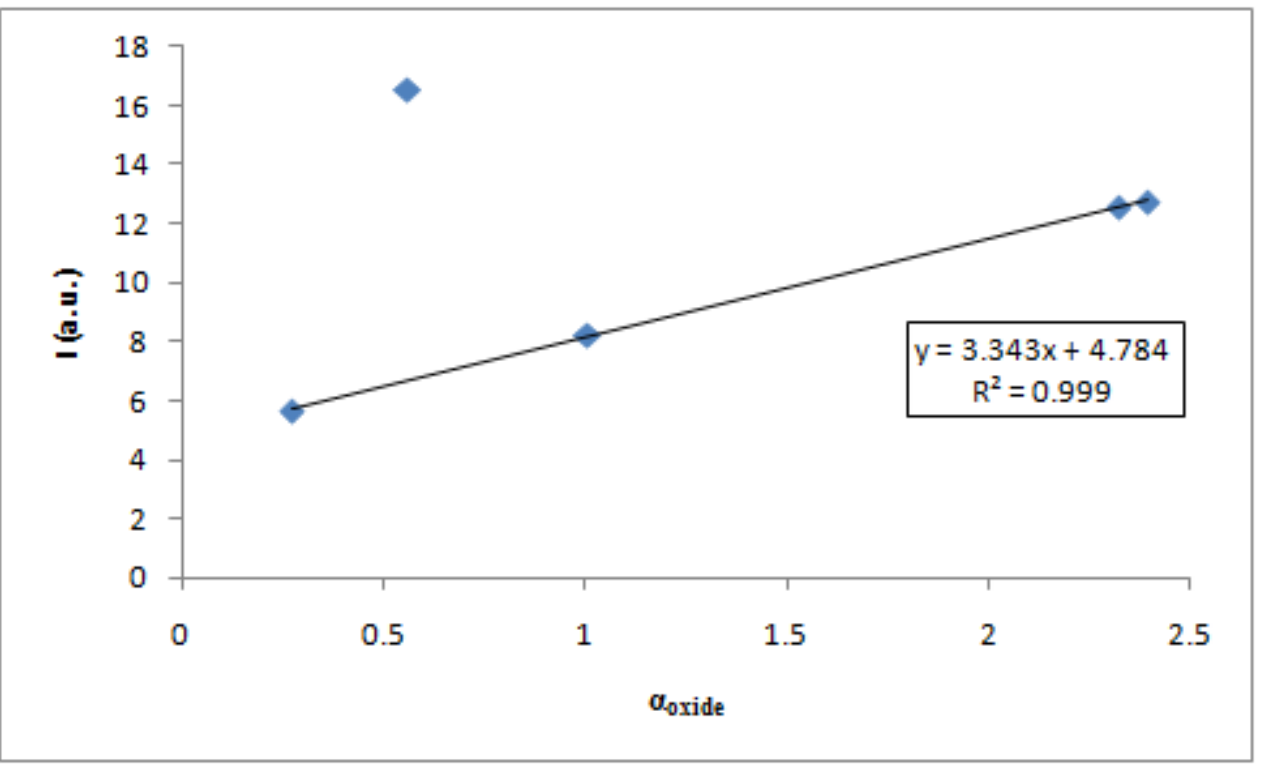

Figure 8

The XRD silicon (111) peak as a function of the coefficient aoxide. 


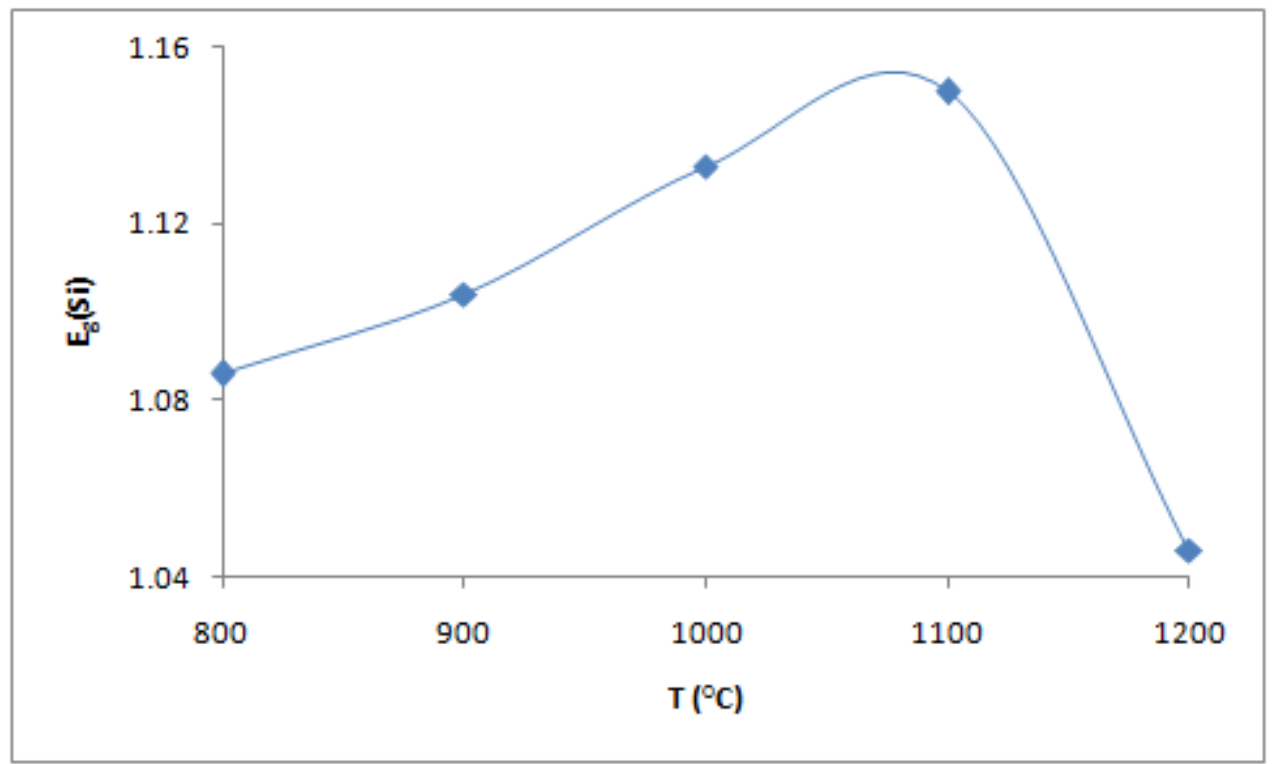

\section{Figure 9}

The optical band gap of silicon oxide as a function of annealing temperature.

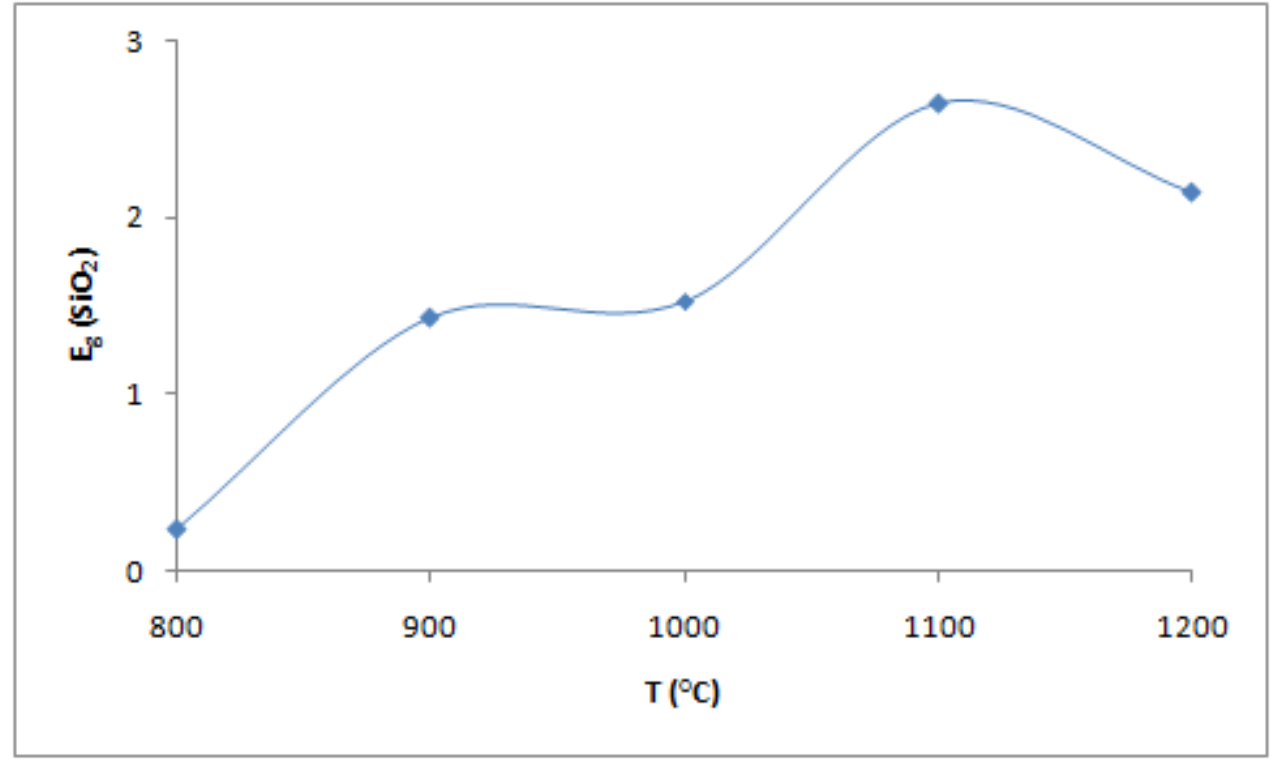

Figure 10

The optical band gap of silicon as a function of annealing temperature. 


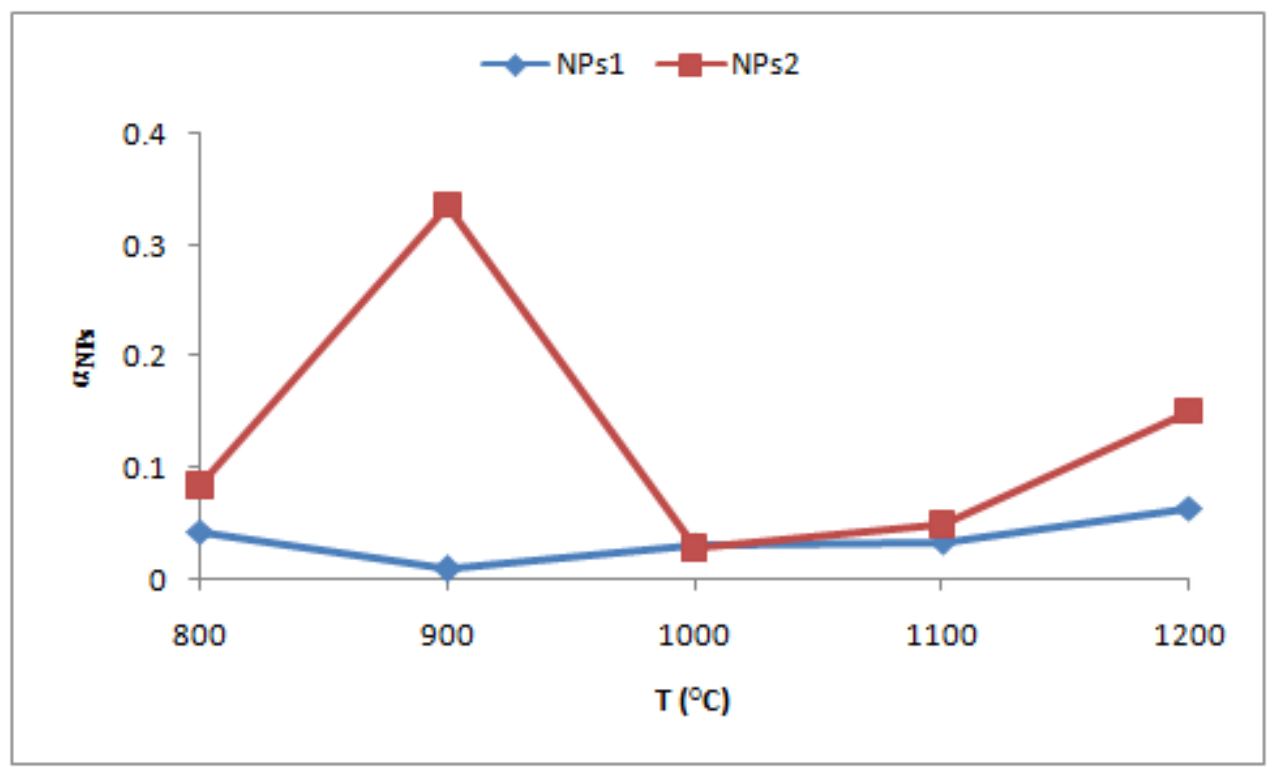

\section{Figure 11}

It is important to assess the effect of the formation of nanoparticles on the optical properties of the prepared samples. For this purpose, we defined the relative absorption coefficients of the nanoparticles observed in the Figs 5 and 6 , in a manner similar to the definition of the relative absorption coefficient of silicon oxide. Fig. 11 illustrates the relative absorption coefficients of the nanoparticles as a function of the annealing temperature. 